УДК 371. 004. 33

Кобися Алла Петрівна

кандидат педагогічних наук, старший викладач

Вінницький державний педагогічний університет імені Михайла Коцюбинського, м. Вінниця, Україна akobysa@ukr.net

\title{
ІНФОРМАЦЙНЕ ОСВІТНС СЕРЕДОВИЩЕ ЯК ПЛАТФОРМА ДЛЯ РЕАЛІЗАЦІЇ ЗМІШАНОГО НАВЧАННЯ У ВИЩИХ НАВЧАЛЬНИХ ЗАКЛАДАХ
}

\begin{abstract}
Анотація. У статті розглянуто організацію змішаного навчання студентів на основі інформаційного освітнього середовища 3 використанням електронних навчальнометодичних комплексів дисциплін, застосування сучасних інформаційних технологій інтерактивного навчання, застосування комп'ютерно-орієнтованих технологій для структурування навчальної інформації і представлення iіi в різних форматах, створення електронного зошита - портфоліо робіт студента з навчальної дисципліни, що дозволяє не тільки якісно оцінити роботу студентів та рівень його компетентності, а й активізувати пізнавальні інтереси за рахунок рефлексії їх особистісної діяльності, самоконтролю i самоперевірки своїх досягнень, аналізу, аргументації та планування подальших дій, рішень i, нарешті, зміни особистісних успіхів за рахунок організації навчальної діяльності у вигляді змішаного навчання.
\end{abstract}

Ключові слова: інформаційне освітнє середовище; електронний навчально-методичний комплекс; змішане навчання; портфоліо робіт студента; інформаційно-комунікаційні технології навчання.

\section{1. ВСТУП}

Постановка проблеми. Однією з головних проблем запровадження інноваційних форм навчання $\epsilon$ вибір оптимального співвідношення найкращих традицій існуючої освітньої системи, сучасних педагогічних інновацій та інструментарію інформаційнокомунікаційних технологій. Як свідчить практика i низка досліджень, тенденція навчання чітко розвивається в напрямі змішаного навчання (blended learning), як процесу, що створює комфортне інформаційне освітнє середовище, системи комунікацій, що надають всю необхідну навчальну інформацію.

У змішаному навчанні значна частина традиційного навчального часу, замінена он-лайн навчальною діяльністю. Он-лайн діяльність може організовуватися, серед іншого, у вигляді надання посилання на ресурси і завантаження текстів і матеріалів, управління он-лайн вікторинами і полегшення подання завдання на самостійну роботу. Отже, під змішаним навчаннями розуміється поєднання формальних засобів навчання (роботи в аудиторіях, вивчення теоретичного матеріалу) й інноваційних (електронних) форм навчання (обговорення за допомогою електронної пошти, Інтернет-конференції, спільної роботи в телекомунікаційному навчальному проекті, створення блог-квестів, виконання практичного завдання і розміщення його результатів на сайті портфоліо тощо), а також безперервним удосконалюванням методів навчання, професійних знань викладачів i студентів. Змішана форма навчання органічно поєднує в собі як традиційні, так й інноваційні форми навчання.

Аналіз останніх досліджень і публікацій. Використанню моделі змішаного навчання в системі освіти присвячені праці вітчизняних і закордонних науковців: А. Андрєєва, В. Бикова, І. Воротникової, Є. Желнової, Е. Кадирової, М. Кадемії, Н. Корсунської, В. Кухаренка, М. Мохової, М. Нікітіної, О. Рафальської, В. Солдаткіна, О. Спіріна, О. Тіхомірової, Ю. Триуса, Г. Чередніченко, Л. Шапрана та ін. 
У роботах В. Кухаренка звертається увага на організацію і використання дистанційного навчання, М. Кадемія наводить характеристики різних інноваційних методик навчання (e-learning, m-learning, u-learning, f-learning), В. Биков досліджував моделі організаційних систем відкритої освіти, Ю. Триус аналізував системи мобільного і комбінованого навчання, О. Спірін описував використання хмарних технологій, електронних бібліотек, інформаційного освітнього середовища.

Мета статті - розглянути можливості організації навчальної діяльності студентів 3 використанням моделі змішаного навчання на основі інформаційного освітнього середовища, сучасних засобів телекомунікацій і технології портфоліо студента 3 навчальної дисципліни.

\section{2. РЕЗУЛЬТАТИ ДОСЛІДЖЕННЯ}

Змішане навчання як інструмент модернізації сучасної освіти на практиці реалізується в створенні нових педагогічних методик, що основані на інтеграції традиційних підходів організації навчального процесу, де здійснюється передавання знань, та технології електронного навчання.

На думку К. Куна, метою змішаного навчання є намагання об'єднати переваги очного навчання й електронних ресурсів [1, с. 16]. Моебз і Вейбелзах (Moebs \& Weibelzahl) визначають змішане навчання як «поєднання дистанційного і традиційного спілкування в інтегрованій навчальній діяльності» [2, с. 3]. На думку Грехема (Graham, C.R.), змішане навчання - це підхід, який інтегрує традиційне навчання і комп'ютерно опосередковане навчання в педагогічному середовищі [3, c. 5] .

За визначенням В. М. Кухаренка, змішане навчання - це цілеспрямований процес здобування знань, умінь та навичок в умовах інтеграції аудиторної і позааудиторної навчальної діяльності суб'єктів освітнього процесу на основі використання і взаємного доповнення технологій традиційного, електронного, дистанційного та мобільного навчання за наявності самоконтролю студента за часом, місцем, маршрутами та темпом навчання [4].

Отже, змішана модель навчання - це модель використання розподілених інформаційно-освітніх ресурсів у стаціонарному навчанні із застосуванням елементів асинхронного й синхронного дистанційного навчання, яке практикується як елемент стаціонарного навчання під час проведення аудиторних занять і в самостійній роботі студентів. Виходячи з цього, змішане навчання успадковує в собі елементи дистанційного навчання, але, у свою чергу, виключає його недоліки.

Саме таку модель навчання застосовують у своїй професійній діяльності викладачі кафедри інноваційних та інформаційних технологій в освіті Вінницького державного педагогічного університету імені Михайла Коцюбинського. Для технічного забезпечення змішаної моделі навчання ми застосовуємо сучасну комп'ютерну й організаційну техніку (веб-камери, інтерактивні дошки, плазмові панелі тощо).

Інформаційне освітнє середовище організовано на базі навчального порталу кафедри, який розміщено на виділеному сервері. Загальний обсяг інформації порталу складає більше 500 Гб. Доступ до інформаційно-освітнього порталу здійснюється як 3 головного сайту університету (розділ Інститут та факультети), так і засобами відомих пошукових систем (Google, Яндекс, Мета тощо).

Структура інформаційно-освітнього порталу має такі розділи: 


\begin{tabular}{|c|c|}
\hline Загальні відомості: & Навчальна робота: \\
\hline $\begin{array}{l}\checkmark \text { абітурієнту; } \\
\checkmark \text { програми; } \\
\checkmark \text { ЕНМК; } \\
\checkmark \text { програмно-педагогічні засоби; } \\
\checkmark \text { рейтинг членів кафедри; } \\
\checkmark \text { електронна газета. }\end{array}$ & $\begin{aligned} \checkmark & \text { упровадження Болонської декларації } \\
& \text { в навчальний процес; } \\
\checkmark & \text { державна атестація освітньо- } \\
& \text { кваліфікаційних працівників; } \\
\checkmark & \text { підготовка до екзаменів; } \\
\checkmark & \text { дипломні і курсові роботи тощо. }\end{aligned}$ \\
\hline 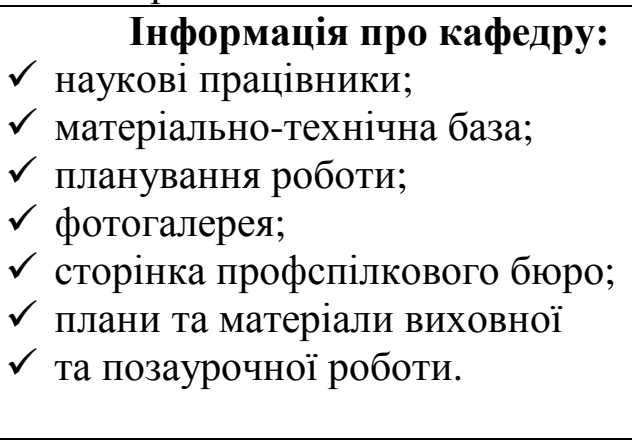 & \begin{tabular}{ll}
\multicolumn{1}{c}{ Наукова робота: } \\
$\checkmark$ & напрями і матеріали науково- \\
& дослідної роботи; \\
$\checkmark$ & підготовка науково-педагогічних \\
& працівників; \\
$\checkmark$ & науково-дослідна тема кафедри; \\
$\checkmark$ & експериментальна робота кафедри; \\
$\checkmark$ & Інтел-проекти за програмою \\
& «Навчання для майбутнього» тощо.
\end{tabular} \\
\hline \multicolumn{2}{|c|}{$\begin{array}{l}\checkmark \text { тематика та матеріали виступів, доповідей та методичних семінарів; } \\
\checkmark \text { участь у всеукраїнських та міжнародних конкурсах; } \\
\checkmark \text { співпраця з вітчизняними навчальними закладами; } \\
\checkmark \text { співпраця із зарубіжними навчальними закладами; } \\
\checkmark \text { відкриті заняття викладачів кафедри; } \\
\checkmark \text { видавнича діяльність. }\end{array}$} \\
\hline
\end{tabular}

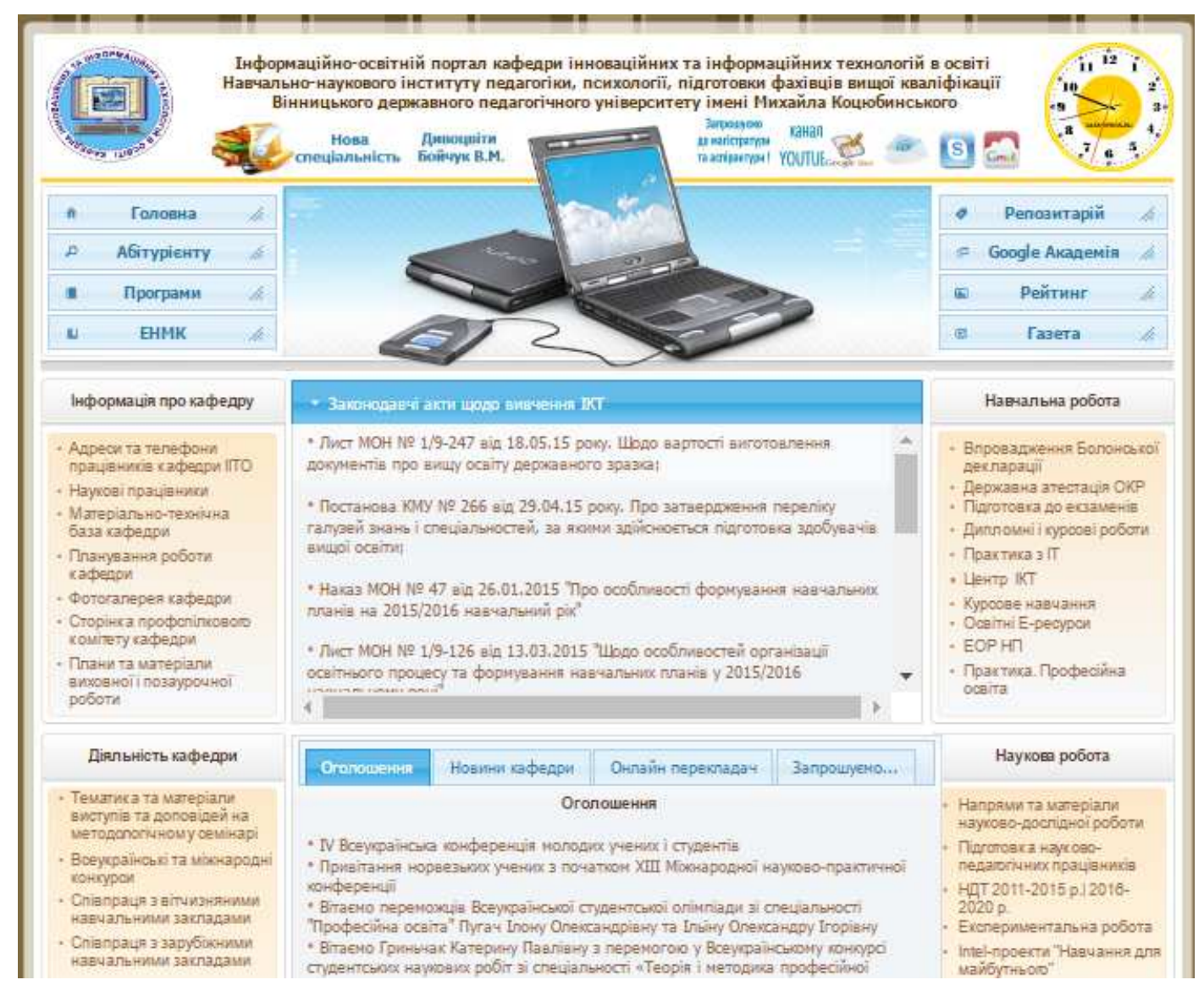

Рис. 1. Вигляд головної сторінки порталу кафедри 
Попри це, для організації самостійної роботи студентів створено бібліотеку педагогічних програмних засобів, до якої віднесено навчальні і довідкові матеріали із загальноосвітніх i професійно-теоретичних дисциплін, які розповсюджуються на дисках. Інформація представлена у формі сайту і дискової медіатеки.

На порталі кафедри в електронному вигляді розміщено електронні педагогічні програмні засоби (навчальні посібники, методичні рекомендації тощо), розроблені викладачами кафедри протягом останніх семи років.

Обов’язковою умовою функціонування порталу є розробка й використання єдиної системи навігації в цьому просторі.

Навчальний контент інформаційно-освітнього порталу кафедри реалізовано у вигляді електронних навчально-методичних комплексів, які структуровані за навчальними роками й освітньо-кваліфікаційними рівнями.

Електронний навчально-методичний комплекс (ЕНМК) - це інформаційний освітній ресурс, який використовується з метою викладу структурованого навчального матеріалу дисципліни, забезпечення поточного контролю, проміжної атестації, а також управління пізнавальною діяльністю студентів у процесі реалізації освітніх програм BH3 [5, c. 56].

Основна мета створення ЕНМК - надати студентам повний комплекс навчальнометодичних матеріалів для здійснення самостійного індивідуального вивчення дисципліни.

ЕНМК призначені для вивчення дисципліни відповідно до навчальної програми, передбачають усі види навчальної діяльності: одержання інформації, практичні заняття, контроль знань студентів та ін.

Технічно кожний електронний навчально-методичний комплекс розроблений у вигляді окремого веб-сайту. Для створення таких програмних продуктів ми використовуємо різне програмне забезпечення, у тому числі Microsoft Office SharePoint Designer (SPD), яке з весни 2009 року є безкоштовним і вільно розповсюджується компанією Microsoft.

Враховуючи специфіку організації навчального процесу вищого навчального закладу, електронний навчально-методичний комплекс у запропонованому нами вигляді, складається $з$ таких блоків:

\begin{tabular}{|l|c|}
\hline \multicolumn{1}{|c|}{ Методичні матеріали: } & Навчальні матеріали: \\
$\checkmark$ анотація; & $\checkmark$ лекції; \\
$\checkmark$ навчальна програма; & $\checkmark$ лабораторні роботи; \\
$\checkmark$ робоча програма. & $\checkmark$ відеоматеріали. \\
\hline Матеріали для контролю знань: & $\checkmark$ Література: \\
$\checkmark$ критерії оцінювання; & $\checkmark$ термінологічний словник; \\
$\checkmark$ тестові завдання; & $\checkmark$ перелік друкованих джерел; \\
$\checkmark$ контрольна робота; & $\checkmark$ Інтернет ресурси; \\
$\checkmark$ питання до заліку; & $\checkmark$ інформація про розробника. \\
$\checkmark$ завдання для самостійної роботи. & \multicolumn{2}{|c|}{ Роботи студентів } \\
\hline \multicolumn{2}{|c|}{} \\
\hline
\end{tabular}

Головна сторінка сайту розроблена на основі вбудованого шаблону у вигляді фреймової структури.

Основною інформаційною складовою ЕНМК є розділ «Навчальні матеріали», до якого віднесено теоретичний матеріал, лабораторні роботи й мультимедійні матеріали. 
Сторінка «Лекції» розроблена у вигляді авторського електронного посібника 3 максимально функціональною панеллю інструментів, що дозволяє працювати 3 нею за допомогою будь-яких мобільних гаджетів (ноутбуків, смартбуків, смартфонів, мобільних телефонів, графічних планшетів тощо), які активно використовують сучасні студенти у повсякденному житті, що збільшує можливості розповсюдження i опрацювання навчального матеріалу.

Зміст кожної з лекцій містить, попри текстовий матеріал схем, малюнки, моделей, відеоматеріалів у формі скрінкастів, перелік літератури 3 даного питання тощо. Для візуалізації i підвищення рівня запам'ятовування навчального матеріалу він супроводжується мультимедійними навчальними презентаціями, які містять структуровану інформацію з використанням візуальних елементів (інтерактивні схеми, об'єкти Смарт-Арт, діаграми, графіки, а також карти знань тощо). Презентації розроблені з використанням тригерів, тому дозволяють лекторові у зручній формі керувати процесом демонстрації навчального матеріалу на інтерактивних мультимедійних дошках, якими обладнані навчальні аудиторії.

Лабораторні роботи розроблені у форматі електронної книги для самостійного опрацювання за допомогою будь-яких засобів, у форматі .pdf для спрощення процесу друкування і читання за допомогою персонального комп'ютера, а також у форматі docx, для використання у вигляді локального документа. Текст кожної лабораторної роботи містить детальні інструкційні карти для виконання поставленого практичного завдання, які максимально візуалізовані й доповнені скрінкастами, розміщеним на сайті соціального сервісу Youtube.

Матеріали для самостійної роботи розроблені і структуровані так, що студент може вільно виконувати завдання за власною траєкторією і містять значну кількість запитань, завдань, інструкцій та зразків виконання тощо.

До ЕНМК підключено програмне забезпечення для здійснення тестового контролю знань студентів MyTest, за допомогою якого розроблено значну кількість тестових завдань, які студенти можуть скопіювати із сервера кафедри і в автономному режимі проводити самоконтроль знань у зручний час.

У розділі «Роботи студентів» відображені посилання на роботи, виконані студентами під час вивчення навчального матеріалу.

Результати самостійної роботи студентів можуть бути представлені в різних формах, залежно від завдань вивчення дисципліни. Наприклад, під час вивчення дисциплін «Теорія і методика трудового та професійного навчання», «Інформаційнокомунікаційні технології в наукових дослідженнях», «Основи проектних технологій» студенти розробляють проекти за технологіями веб-квестів і блог-квестів, які підключено до електронних навчально-методичних комплексів дисциплін. Це нові технології проектної діяльності, які дозволяють реалізувати колективну роботу.

Під час вивчення дисципліни «Методика застосування комп’ютерної техніки при викладанні предметів шкільного курсу» студенти розробляють телекомунікаційні навчальні проекти за програмою Intel "Навчання для майбутнього" (версія 10.0) із застосуванням соціальних сервісів Інтернет, технологій web 2.0, технологій розподілених обчислень (хмарних технологій) і вікі-технологій. Кожний студент розробляє свій власний проект, який містить блог викладача, значну кількість інтерактивних дидактичних матеріалів (кросвордів, ігор, тестів тощо), інтерактивних on-line опитувальників, карт знань, мультимедійних презентацій, інструкцій тощо.

Під час вивчення студентами спеціальності 015 «Професійна освіта (комп'ютерні технології)» дисципліни «Практикум 3 виробничого навчання», метою якої $\epsilon$ удосконалення навичок практичної роботи 3 апаратним і програмним забезпеченням персонального комп'ютера i використання інформаційних ресурсів комп'ютерних 
мереж ми практикуємо створення електронного зошита - «Портфоліо робіт студента 3 навчальної дисципліни». Реалізується ця технологія на блог-платформі (рис. 2) i містить результати виконання студентом усіх навчальних завдань, самостійної роботи, використання відеоматеріалів та Інтернет-ресурсів, а також самоаналіз власного навчання (рефлексію).

На наш погляд, такий спосіб структурування робіт студента $\epsilon$ не лише ефективною формою самооцінювання результатів навчальної діяльності, рефлексії його особистісної діяльності, самоконтролю і самоперевірки своїх досягнень, аналізу, аргументації і планування подальших дій, рішень i, нарешті, зміни особистісних успіхів (або віри в особистісний успіх), а й спонукає мотивування до навчальних досягнень, набуття досвіду до ділової конкуренції, обгрунтування реалізації самоосвіти і розвитку професійних компетентностей, оцінювання особистісних здібностей.

Створення такого електронного зошита передбачає не тільки виконання практичних завдань, а й аналіз результатів практичної роботи, основних помилок i недоліків, труднощів, що виникли під час практичної роботи.

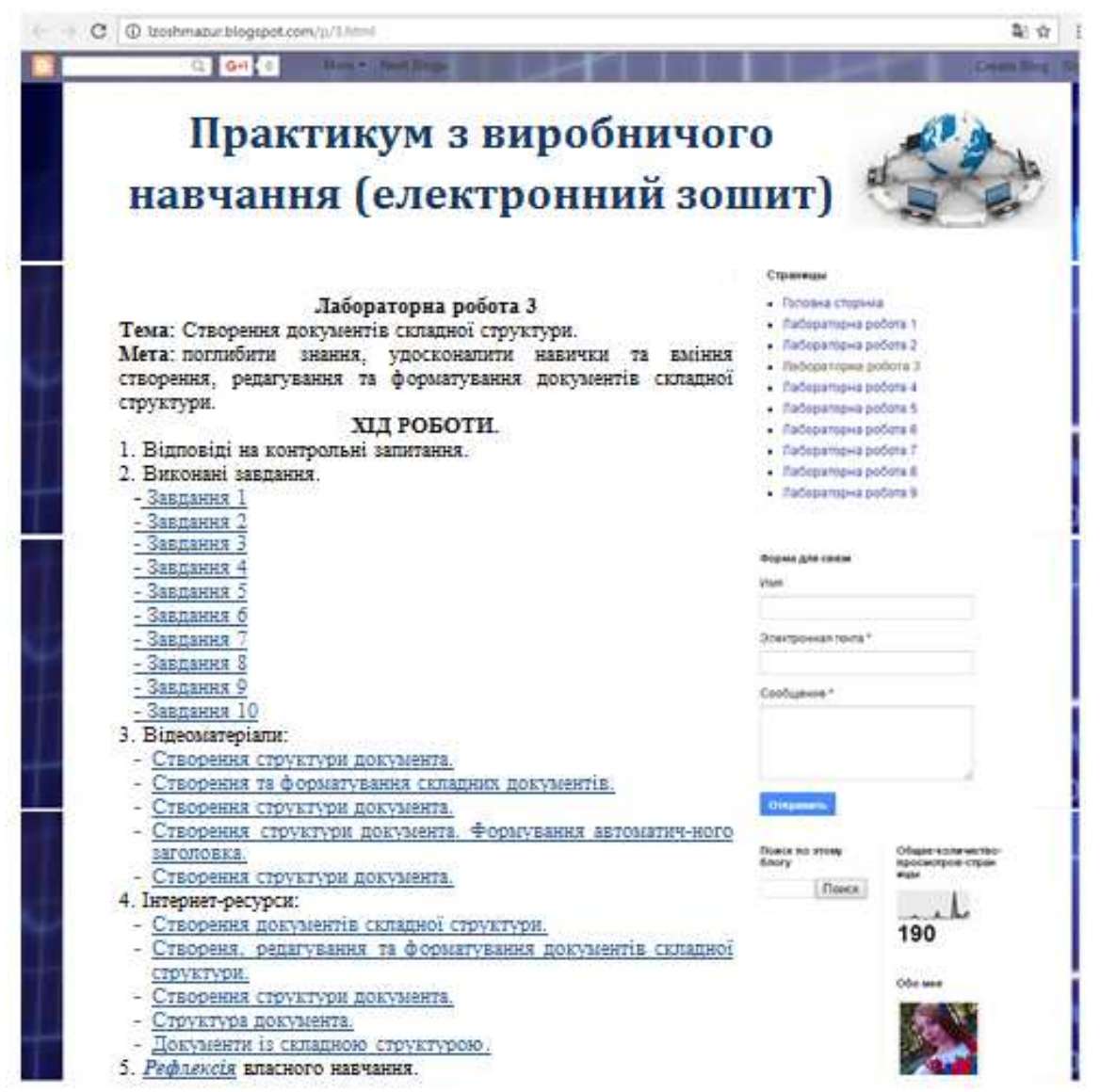

\section{Рис. 2. Вигляд елемента електронного зошита-портфоліо студента} з навчальної дисцииліни

Отже, студенти мають змогу поступово, у міру виконання завдань лабораторних робіт, додавати їх до власних блог-сторінок, брати участь в он-лайн групових обговореннях, вести власний блог із записами, що стосуються власної рефлексії, використовувати всі методичні матеріали, які розмістив викладач на сторінках ЕНМК, заповнювати спільні документи тощо. Перевіряти роботу студентів у такому випадку викладач має змогу в довільний час з будь-якого місця в мережі. 


\title{
3. ВИСНОВКИ ТА ПЕРСПЕКТИВИ ПОДАЛЬШИХ ДОСЛІДЖЕНЬ
}

Модель змішаного навчання має як низку переваг, так і деякі недоліки. До основних переваг слід віднести можливість збору даних і кастомізацію знань й оцінок, одночасне навчання групи студентів, перерозподіл викладачем освітніх інформаційних ресурсів між студентами, розвиток у студентів навичок самостійного навчання $\mathrm{i}$ самоконтролю, підвищує цікавість студентів до отримання знань і якість комунікації між викладачем і студентами. Змішане навчання $є$ більш активним з боку студента, надає йому більше цікавих і пізнавальних можливостей для навчання.

Запропонована методика реалізації змішаного навчання на основі інформаційного освітнього середовища дозволяє використовувати новітні інформаційні технології для організації й підтримки навчального процесу, підвищувати ефективність навчальної діяльності студентів за рахунок упровадження різноманітних телекомунікаційних засобів, активізувати їхні пізнавальні інтереси за рахунок рефлексії їх особистісної діяльності, самоконтролю і самоперевірки своїх досягнень, аналізу, аргументації та планування подальших дій, рішень i, нарешті, зміни особистісних успіхів.

Перспективи подальших досліджень вбачаємо у впровадження в навчальний процес сучасних програмних продуктів, мережевих сервісів, удосконалення структури $\mathrm{i}$ функцій інформаційного освітнього середовища й активного використання технологій розподілених обчислень для розширення можливостей навчальних комп'ютерних комплексів і формування у майбутніх педагогічних працівників навичок застосування інформаційно-комунікаційних технологій у своїй професійній діяльності.

\section{СПИСОК ВИКОРИСТАНИХ ДЖЕРЕЛ}

1. Кун К. E-Learning - электронное обучение // Информатика и образование. - 2006. - №10. - С. 1618.

2. Moebs, S. \& Weibelzahl, S. (2006). Towards a good mix in blended learning for small and medium sized enterprises - Outline of a Delphi Study. Proceedings of the Workshop on Blended Learning and SMEs held in conjuction with the 1stEuropean Conference on Technology Enhancing Learning Crete, Greece, Pp. $1-6$.

3. Graham, C.R. (2005). Blended learning system: Definition, current trends and future direction. In: Bonk, C.J., Graham, C.R. (eds.) Handbook of Blended Learning: Global Perspectives, Local Designs, pp. 3-21. Pfeiffer, San Francisco.

4. Кухаренко В. М. Змішане навчання. Вебінар. [Електронний ресурс] /Володимир Миколайович Кухаренко/ - Режим доступу : http://www.wiziq.com/online-class/2190095-intel-blended..

5. Технології дистанційного навчання: словник-глосарій / укладачі М. Ю. Кадемія, В. М. Кобися. Вінниця : ФОП Тарнашинський О. В., 2016. - 284 с.

Матеріал надійшов до редакиї 29.11.2016 p.

\section{ИНФОРМАЦИОННАЯ ОБРАЗОВАТЕЛЬНАЯ СРЕДА КАК ПЛАТФОРМА ДЛЯ РЕАЛИЗАЦИИ СМЕШАННОГО ОБУЧЕНИЯ В ВЫСШИХ УЧЕБНЫХ ЗАВЕДЕНИЯХ}

\author{
Кобыся Алла Петровна \\ кандидат педагогических наук, старший преподаватель \\ Винницкий государственный педагогический университет имени Михайла Коцюбинского, \\ г. Винница, Украина \\ akobysa@gmail.com
}




\begin{abstract}
Аннотация. В статье рассмотрена организация смешанного обучения студентов на основе информационной образовательной среды с использованием электронных учебнометодических комплексов дисциплин, применения современных информационных технологий интерактивного обучения, компьютерно-ориентированных технологий для структурирования учебной информации и представления ее в разных форматах, создание электронного пособия - портфолио работ студента по учебной дисциплине, которое позволяет не только качественно оценить работу студентов и уровень их компетентности, но и активизировать познавательные интересы за счет рефлексии их личностной деятельности, самоконтроля и самопроверки своих достижений, анализа, аргументации и планирования дальнейших действий, решений и, наконец, изменения личностных успехов.
\end{abstract}

Ключевые слова: информационная образовательная среда; электронный учебнометодический комплекс; смешанное обучение; портфолио работ студента; информационнокоммуникационные технологии обучения.

\title{
INFORMATION EDUCATIONAL ENVIRONMENT AS A PLATFORM FOR IMPLEMENTING BLENDED LEARNING IN HIGHER EDUCATION INSTITUTIONS
}

\author{
Alla P. Kobysia \\ $\mathrm{PhD}$ (in Education), Senior Lecturer \\ Vinnitsa State Pedagogical University, Vinnitsa, Ukraine \\ akobysa@gmail.com
}

\begin{abstract}
The article deals with the organization of blended learning for students on the basis of information educational environment using electronic teaching methods courses. It was considered the use of modern information technology, interactive learning, the use of computer-oriented technologies for structuring educational information and presenting it in different formats, creating an electronic notebook - portfolio of student's work on appropriate discipline. The portfolio does not only qualitatively assess the performance of students and their level of competence, but also intensify educational interests through the reflection of their professional activity, self-control and self-monitoring their achievement, analysis, reasoning and planning future actions, decisions, and finally changes personal success.
\end{abstract}

Keywords: information educational environment; electronic educational-methodical complex; blended learning; portfolio of work the student; ICT training.

\section{REFERENCES (TRANSLATED AND TRANSLITERATED)}

1. Kun K. E-Learning - electroning learning // Informatika i obrazovanie.- 2006. - №10. - P.16-18. (in Ukrainian)

2. Moebs, S. \& Weibelzahl, S. (2006). Towards a good mix in blended learning for small and medium sized enterprises - Outline of a Delphi Study. Proceedings of the Workshop on Blended Learning and SMEs held in conjuction with the 1stEuropean Conference on Technology Enhancing Learning Crete, Greece, pp 1 -6. (in English)

3. Graham, C.R. (2005). Blended learning system: Definition, current trends and future direction. In: Bonk, C.J., Graham, C.R. (eds.) Handbook of Blended Learning: Global Perspectives, Local Designs, pp.3-21. Pfeiffer, San Francisco. (in English)

4. Kukharenko V.M. Blended learning. Webinar. [online] / Volodymyr Mykolaiovych Kukharenko / Available from: http://www.wiziq.com/online-class/2190095-intel-blended. (in Ukrainian)

5. Technology Distance Learning: Dictionary and Glossary / ukladachi M. Iu. Kademiia, V. M. Kobysia. Vinnytsia: FOP Tarnashynskyi O. V., 2016. - 284 p. (in Ukrainian)

Conflict of interest. The author has declared no conflict of interest.

\section{$(c))$ EY-NC-SA}

This work is licensed under Creative Commons Attribution-NonCommercial-ShareAlike 4.0 International License. 